\title{
Knowledge, Attitudes and Practices of Adults in the United Arab Emirates Regarding Helicobacter pylori induced Gastric Ulcers and Cancers
}

\author{
Abdullah Imadeddin Malek*, Muzan Abdelbagi, Lian Odeh, Atheer Tariq \\ Alotaibi, Mohamed Husain Alfardan, Hiba Jawdat Barqawi
}

\begin{abstract}
Objective: The aim of this study is to assess the current level of knowledge, as well as the attitudes and practices (KAP) of the adult population in Sharjah, UAE with regards to $H$. pylori induced gastric ulcers and gastric cancers. Methods: A cross sectional study of 500 participants was conducted in public venues in Sharjah, UAE through the distribution of a self-administered questionnaire English and Arabic speaking residents aged 18 years and above of both sexes were invited to participate in this study via convenience sampling. Responses were collected and analyzed using SPSS. Results: General knowledge about H. pylori was poor, only $24.6 \%$ had heard of H. pylori. $61 \%$ of the participants did not know the link between $H$. pylori and gastric cancer. Only 3\% of the participants associated psychological stress with gastric ulcer development. Females had higher knowledge scores $\left(p=0.008^{*}\right)$. Participants with a medical background typically had higher knowledge scores than their peers in other fields of work $(\mathrm{p}<0.0001 *)$. Participants' attitudes towards $H$. pylori were suboptimal with only $33 \%$ willing to seek medical help If they get symptoms. Majority of participants with an approximate of $84 \%$ showed an overall average to excellent practices towards $H$. pylori. Conclusion: General awareness about H. pylori induced gastric ulcers and cancers is poor. The results of this study can be a starting point to devise new education programs and campaigns that raise awareness of this health issue which could be easily avoided with prevention, early detection, and intervention.
\end{abstract}

Keywords: Helicobacter pylori- gastric ulcers- gastric cancers- public health- community health

Asian Pac J Cancer Prev, 22 (5), 1645-1652

\section{Introduction}

One million deaths worldwide can be annually attributed to gastric ulcers and gastric cancer, specifically in low- to middle-income populations (Ferlay et al., 2015; Plummer et al., 2016). Helicobacter pylori (H. pylori) infection and non-steroidal anti-inflammatory drugs (NSAIDs) are the most common risk factors for the development of gastric ulcers (Kuna et al., 2019). H. pylori is a gram-negative bacillus that can survive in the gastric mucosa and contribute to significant inflammation and tissue damage due to a multitude of virulence factors. Globally, H. pylori is believed to infect more than half of the world's population with high geographical variability (Hooi et al., 2017). H. pylori prevalence of $74-78 \%$ has been reported in the asymptomatic population of the UAE (Eshraghian, 2014). To the best of our knowledge, no similar data that assess knowledge, attitudes and prevalence have been documented in the UAE. Since most patients remain asymptomatic for a long period of time, long-term colonization of the gastric mucosa is thought to be an important factor in the future development of several diseases such as chronic gastritis, peptic ulcer disease, gastric cancer, and mucosa-associated lymphoid tissue (MALT) lymphoma (Cover and Blaser, 2009; Muhammad et al., 2013). The progression of H. pylori to gastric cancer is a complex multistep process that may take decades to develop from chronic gastritis to atrophic gastritis to intestinal dysplasia and eventually, cancer. This latency period offers a window of opportunity for early detection and eradication of $H$. pylori prior to the manifestation of any complications. Three cohort studies led to the classification of $H$. pylori as a class I carcinogen by the World Health Organization (WHO) (Moss, 2017). A meta-analysis conducted by Plummer et. Al. reported that $89.0 \%$ of non-cardia gastric cancer was attributable to $H$. pylori (Plummer et al., 2016). Despite the overall decline in the incidence and mortality rates of gastric cancer around the world, it remains a major health concern. Gastric cancer is the fifth most 
common cancer in the world ("Cancer today", 2020) and is responsible for 783,000 deaths globally, making it the third most common cause of death due to cancer (Bray et al., 2018). Eradication of $H$. pylori involves a standard triple therapy that consists of a proton pump inhibitor, clarithromycin and either metronidazole or amoxicillin. Successful eradication and treatment of $H$. pylori leads to regression of acute and chronic inflammation ( $\mathrm{Li}$ et al., 2017), healing of gastric ulcers (Ford et al., 2016; Leodolter et al., 2001) and prevention of gastric cancer (Wong et al., 2004). However, the success rates of the standard therapy have become suboptimal in many parts of the world falling below an acceptable level of $80 \%$ (Graham et al., 2007). This could be attributed to antibiotic resistance, patient noncompliance and several host or bacterial factors that may hinder the efficacy of eradication (Kim et al., 2015). There is a generalized consensus regarding poor knowledge and awareness of the general population about the impending effects of H. pylori and its possible complications (Chen et al., 2005) (Oh et al., 2009) (Shin et al., 2013) (Wynne et al., 2013). Attitudes related to $H$. pylori infection were unexpected. Some studies have assessed the perception of self-risk of their participants. Most have viewed their risk of contracting $H$. pylori infection and developing stomach cancer as "similar to" or lower than their peers of the same gender and age (Oh et al., 2009) (Wynne et al., 2013) while others did not believe they would be infected with $H$. pylori although its prevalence was around $40 \%$ in that environment (Xia et al., 2012). Commonly, good habits are being practiced and have been associated with less risks of $H$. pylori infection (Lee et al. 2012). These studies found the inadequate number of publications regarding $H$. pylori surprising given the fact that gastric cancer attributed to $H$. pylori infection can be prevented through strategies like screening and early treatment. This study aims to assess the current level of KAP of the residents of Sharjah, UAE with regards to $H$. pylori gastric ulcers with the intent to promote early detection and eradication and raise awareness about the dangers of untreated $H$. pylori infection.

\section{Materials and Methods}

\section{Research design}

A descriptive, cross-sectional research design was implemented to assess the levels of KAP of the population in Sharjah, UAE, with regards to gastric ulcers and H. pylori.

\section{Questionnaire design}

Considering the lack of current tools evaluating H. pylori KAPs, particularly among high-risk populations, a tool was developed by the authors using the World Health Organization Guide to Developing Knowledge, Attitude, and Practice Surveys (WHO, 2008). Additionally, literature and international studies were used for further guidance on how to structure the questionnaire (Canbaz, Sunter, Peksen and Leblebicioglu, 2005) (Ahmed, Salih, Jafri, Ali Shah and Hamid, 2009) (Abebaw et al., 2014) (Tsongo et al., 2015) (Driscoll et al., 2017) (Cano-Contreras et al., 2018)
(Wu et al., 2020). The questionnaire was developed in English then translated to Arabic.

The questionnaire included 18 questions and consisted of 4 sections: demographics (8), knowledge (6), attitudes (2), and practices (2) of the population in Sharjah towards H. Pylori. Demographics questions collected data regarding the gender, age, nationality, educational level, and field of work of the participants. Participants were also asked about any current symptomatology or any previous health conditions. Knowledge was assessed using multiple choice questions that aimed to gauge the level of knowledge the participants had with regards to gastric ulcers generally and $H$. pylori specifically. Attitudes regarding the prevention of gastric ulcers and avoiding infection by $H$. pylori were also assessed using multiple choice questions and a 3-point Likert scale. Practices included multiple choice questions about practices the participants engaged in on a regular basis.

\section{Sampling and pilot study}

A minimum sample size of 385 was calculated based on $5 \%$ marginal error and $50 \%$ prevalence using the following formula: where $\mathrm{n}=$ sample size, $\mathrm{p}=$ expected prevalence, and $\mathrm{SE}=$ sampling error. . A pilot study was initially conducted with 25 volunteers. After modification and review, based on feedback from the pilot study, the questionnaire was approved by the Ethics Committee in the University of Sharjah prior to distribution (Validation number: REC-16-12-21-02-S).

\section{Data collection process}

Before data collection, the authors considered practical issues that may affect the precision of the study. These issues could be withdrawal, failure, or refusal to give valid responses to particular items in the questionnaire. Henceforth, to avoid any degree of attrition and achieve a desired sample size, 525 residents were approached in the city of Sharjah, a major city in the UAE, in public venues such as parks, residential compounds, and shopping malls, via convenience sampling. An information sheet was provided to the participants indicating the significance of the study and its objectives. Participants were approached based on availability and willingness to participate in the study. Inclusion criteria were UAE residents (both locals and expatriates), aged 18 years or more who can communicate in Arabic or English. Participants who did not match these criteria were excluded. Induction training was provided to all researchers regarding data collection and a standardization process was implemented to ensure answers to all enquiries are calibrated. This included obtaining written informed consent, then handing the questionnaire and giving the participants time and privacy to answer questions. Data collectors were available to answer any inquiries and clarify any ambiguities. If the participants had problems understanding one of the questions, a standard explanation was provided by the researchers to avoid leading and biased questions. Confidentiality was maintained as the collected data was only available to the researchers. 
DOI: 10.31557/APJCP.2021.22.5.1645

KAP Regarding Helicobacter Pylori Induced Gastric Ulcers and Cancers

\section{Statistical analysis}

Data was entered and analyzed using the Statistical Package for Social Sciences (SPSS) Version 21 software (IBM Corp., Armonk, NY, USA). Scores were generated for knowledge, attitudes, and practices to allow for easier comparison and correlation. The total knowledge score was calculated by giving one point to every true statement chosen by the participants. Incorrect statements were not awarded. Participants were stratified based on their total scores as excellent $(>66 \%)$, average $(33-66 \%)$ and poor $(<33 \%)$. The same system was implemented to assess participants' attitudes and practices. Data was expressed in the form of frequencies and percentages where applicable. A variety of inferential statistical tests were employed to study the relationship between variables including Chi-square for categorical data. ANOVA and Student's t-tests were conducted to compare mean scores among the different groups. A p-value of $\leq 0.05$ was considered to be statistically significant. Quantitative variables were reported as a mean \pm standard deviation if the data was in normal distribution. Median values were reported if the data was not in normal distribution.

\section{Results}

The questionnaire was distributed to 525 participants, 500 questionnaires were completed, yielding a response rate of $95 \%$ (females $=58 \%$, males $=42 \%$ ). The majority, $83.4 \%$ of our participants have received or are currently pursuing higher degree education. The rest of the participants have attained only primary or secondary education in school. As for occupation, 9.9\% of participants were found to be healthcare professionals. The socio-demographic data of the participants are summarized in Table 1.

\section{General knowledge regarding $H$. pylori}

General knowledge about $H$. pylori was generally poor among the target population. Remarkably, only $24.6 \%$ have previously heard of $H$. pylori, of which $79.2 \%$ were participants from medical backgrounds.

We assessed the general knowledge of the population with regards to stomach ulcers and the bacterium $H$. pylori and its health impacts. While $39 \%$ of the population recognized the relationship between $H$. pylori and gastric cancer, $48.8 \%$ of our participants were aware of the association between $H$. pylori and gastric ulcers. Only $45 \%$ of the participants reported that bacterial infections could lead to the development of a stomach ulcer. Interestingly, only $27.8 \%$ recognized the link between the use of medications such as NSAIDs on the development of stomach ulcers and approximately $40 \%$ did not recognize the link between poor practices and lifestyle choices and stomach ulcer development. Surprisingly, only $3 \%$ of the participants thought that stress could be linked to stomach ulcer development.

Other common causes of stomach ulcers as reported by our participants are summarized in Table 2 .

The level of knowledge among different sets of groups including gender, educational level and field of work were compared using unpaired t-test, as seen in Table 3. Females
Table 1. Demographic Data of Participants in the Study

\begin{tabular}{|c|c|c|}
\hline Demographic variable & Frequency & Respondents' (\%) \\
\hline \multicolumn{3}{|l|}{ Gender } \\
\hline Male & 210 & $42.10 \%$ \\
\hline Female & 289 & $57.90 \%$ \\
\hline \multicolumn{3}{|l|}{ Age } \\
\hline $18-29$ & 185 & $37.40 \%$ \\
\hline $30-39$ & 174 & $35.20 \%$ \\
\hline $40+$ & 136 & $27.50 \%$ \\
\hline \multicolumn{3}{|l|}{ Nationality } \\
\hline Emirati & 58 & $12.00 \%$ \\
\hline Arab & 290 & $60.20 \%$ \\
\hline Non-Arab & 134 & $27.80 \%$ \\
\hline \multicolumn{3}{|l|}{ Educational level } \\
\hline Elementary school & 7 & $1.50 \%$ \\
\hline High school & 73 & $15.10 \%$ \\
\hline University student & 134 & $27.80 \%$ \\
\hline University graduate & 268 & $55.60 \%$ \\
\hline \multicolumn{3}{|l|}{ Emirate } \\
\hline Abu Dhabi & 21 & $4.20 \%$ \\
\hline Dubai & 70 & $14.00 \%$ \\
\hline Sharjah & 379 & $75.80 \%$ \\
\hline $\begin{array}{l}\text { Rest of Northern } \\
\text { Emirates }\end{array}$ & 30 & $6.00 \%$ \\
\hline \multicolumn{3}{|l|}{ Field of work } \\
\hline Medical & 48 & $9.90 \%$ \\
\hline Non-Medical & 438 & $90.10 \%$ \\
\hline
\end{tabular}

had higher average knowledge scores (58.22\%) compared to males $(56.25 \%)\left(\mathrm{p}=0.008^{*}\right)$. Compared to participants with a non-medical background (56.74\%), those who are in different medical fields $(64.08 \%)$ had a higher average knowledge score $(\mathrm{p}<0.0001 *)$. The educational level did not contribute to the level of knowledge of our participants $(p=0.8271)$ as reported in the same table. When asked about remedies they would engage in or suggest to others to relieve symptoms of stomach ulcers, $55.8 \%$ incorrectly

Table 2. Responses about Possible Causes of Gastric Ulcers

\begin{tabular}{lcc}
\hline Remedies & Frequency & Respondents\% $\%$ \\
\hline Drinking milk & 221 & $44.20 \%$ \\
Using an antacid & 174 & $34.80 \%$ \\
Drinking water & 241 & $48.20 \%$ \\
Using anti-inflammatory & 33 & $6.60 \%$ \\
medications & & \\
Drinking 7-up & 63 & $12.60 \%$ \\
Sleeping on the stomach & 47 & $9.40 \%$ \\
Seeking medical help & 165 & $33 \%$ \\
Herbal drinks & 174 & $34.80 \%$ \\
Eating & 57 & $11.40 \%$ \\
Ignoring it & 50 & $10 \%$ \\
\hline
\end{tabular}

Asian Pacific Journal of Cancer Prevention, Vol 221647 
Table 3. Knowledge Scores among Ddifferent Groups Including Gender, Educational Level, and Field of Work

\begin{tabular}{|c|c|c|c|c|c|}
\hline Demographic variable & Frequency & Respondents' (\%) & Knowledge Score (\%) & Test value & $\mathrm{p}$-value \\
\hline \multicolumn{6}{|l|}{ Gender } \\
\hline Male & 210 & $42.10 \%$ & $56.25 \%$ & $2.901 *$ & 0.008 \\
\hline Female & 289 & $57.90 \%$ & $58.22 \%$ & & \\
\hline \multicolumn{6}{|l|}{ Educational level } \\
\hline School Graduates & 80 & $16.60 \%$ & $56.91 \%$ & $0.7190 *$ & 0.8271 \\
\hline Higher Education & 402 & $83.40 \%$ & $57.98 \%$ & & \\
\hline \multicolumn{6}{|l|}{ Field of work } \\
\hline Medical & 48 & $9.90 \%$ & $64.08 \%$ & $6.695^{*}$ & $<0.0001$ \\
\hline Non-Medical & 438 & $90.10 \%$ & $56.74 \%$ & & \\
\hline
\end{tabular}

Table 4. Remedies Recommended or Used by Participants to Alleviate Symptoms of Gastric Ulcers

\begin{tabular}{lcc}
\hline Remedies & Frequency & Respondents'\% \\
\hline Drinking milk & 221 & $44.20 \%$ \\
Using an antacid & 174 & $34.80 \%$ \\
Drinking water & 241 & $48.20 \%$ \\
Using anti-inflammatory & 33 & $6.60 \%$ \\
medications & & \\
Drinking 7-up & 63 & $12.60 \%$ \\
Sleeping on the stomach & 47 & $9.40 \%$ \\
Seeking medical help & 165 & $33 \%$ \\
Herbal drinks & 174 & $34.80 \%$ \\
Eating & 57 & $11.40 \%$ \\
Ignoring it & 50 & $10 \%$ \\
\hline
\end{tabular}

said they would suggest drinking milk which could relieve symptoms of gastroesophageal reflux or heartburn but not symptoms of stomach ulcers. Similarly, 34.8\% would suggest using an antacid for relief of stomach ulcer symptoms, a drug commonly used to relieve symptoms of acid reflux. Other remedies our participants reported are summarized in Table 4.

Knowledge about routes of transmission of stomach bacteria such as $H$. pylori was also relatively poor. Few recognized low socioeconomic conditions $(23.2 \%)$ and overcrowding, sharing utensils and toothbrushes (26.6\%), contaminated water sources and food $(46.2 \%)$ as possible routes of transmission.

We evaluated the knowledge of the participants regarding $H$. pylori and its possible health impacts. Participants were asked to point out diseases that could develop as a result of $H$. pylori infection: $49.3 \%$ recognized the link between stomach ulcers and H. pylori; $45.5 \%$ recognized the link between duodenal ulcers and

Table 5. Sources of Knowledge towards H. pylori, Its Routes of Transmission, Prevention, and Associated Diseases.

\begin{tabular}{lcc}
\hline Source of knowledge & Frequency & Respondents'\% \\
\hline Personal reading & 103 & $20.70 \%$ \\
Social media & 74 & $14.90 \%$ \\
Mass media & 41 & $8.30 \%$ \\
(News, TV, and radio) & & \\
\hline
\end{tabular}

Table 6. General Attitudes of Participants towards Prevention of $H$. pylori Infection

\begin{tabular}{lcc}
\hline Attitudes & Frequency & Percentage (\%) \\
\hline $\begin{array}{l}\text { Ensure clean water and food } \\
\text { consumption }\end{array}$ & 378 & $75.60 \%$ \\
Improve self-hygiene & 311 & $62.20 \%$ \\
Getting frequent checkups & 305 & $61 \%$ \\
Avoid sharing utensils & 249 & $49.80 \%$ \\
None of the above & 11 & $2.20 \%$ \\
\hline
\end{tabular}

Table 7. Effect of the Severity of Symptoms Experienced by the Participants on Their Positive Attitudes towards Prevention, Early Detection, and Management of $H$. pylori

\begin{tabular}{lccc}
\hline Severity of Symptoms & $\begin{array}{c}\text { Attitude } \\
\text { Score (\%) }\end{array}$ & $\begin{array}{c}\text { Test } \\
\text { value }\end{array}$ & p-value \\
\hline Mild & $53.23 \%$ & $2.685^{* *}$ & 0.0208 \\
Moderate & $53.38 \%$ & & \\
Severe & $57.63 \%$ & & \\
\hline
\end{tabular}

**Test is ANOVA test

H. pylori, only $8.3 \%$ suggested that dyspepsia could develop as a result of $H$. pylori infection. Renal failure, a common health effect of $H$. pylori was only reported by $9.7 \%$ of our population. Alarmingly, only $39.4 \%$ of the participants recognized gastric cancer as a sequelae of $H$. pylori induced gastric ulcer.

Family and friends (34.7\%) and place of study (28.1\%) were the most frequently reported sources of information about $H$. pylori induced gastric ulcer. Rest of the resources could be seen in Table 5 .

\section{Attitudes towards H. pylori}

Participants' attitudes regarding $H$. pylori infection were suboptimal, only $33 \%$ of the population said they would seek medical help or suggest it to others in the event of suffering from symptoms suggestive of stomach ulcers. However, 76.2\% claimed they would undergo an endoscopy to further assess stomach ulcers in case they were diagnosed with $H$. pylori despite the discomfort associated with it. General attitudes of the participants towards preventing acquiring $H$. pylori are summarized in Table 6. 
DOI: 10.31557/APJCP.2021.22.5.1645

KAP Regarding Helicobacter Pylori Induced Gastric Ulcers and Cancers

Table 8. Practice Scores among Different Groups, Including Gender, Educational Level, and Field of Work.

\begin{tabular}{|c|c|c|c|c|c|}
\hline Demographic variable & Frequency & Respondents' (\%) & Practice Score (\%) & Test value & $\mathrm{p}$-value \\
\hline \multicolumn{6}{|l|}{ Gender } \\
\hline Male & 210 & $42.10 \%$ & $72.72 \%$ & $4.876^{*}$ & $<0.0001$ \\
\hline Female & 289 & $57.90 \%$ & $81.28 \%$ & & \\
\hline \multicolumn{6}{|l|}{ Educational level } \\
\hline School Graduates & 80 & $16.60 \%$ & $75.11 \%$ & $1.18^{*}$ & 0.2377 \\
\hline Higher Education & 402 & $83.40 \%$ & $78 \%$ & & \\
\hline \multicolumn{6}{|l|}{ Field of work } \\
\hline Medical & 48 & $9.90 \%$ & $78.08 \%$ & $0.1787^{*}$ & 0.8582 \\
\hline Non-Medical & 438 & $90.10 \%$ & $77.55 \%$ & & \\
\hline
\end{tabular}

Attitudes regarding the prevention of $H$. pylori and stomach ulcers, reported in Table 7 using ANOVA test, were significantly better in patients who suffered from ALARM symptoms in comparison to those who did not $\left(\mathrm{F}(2,497)=2.685, \mathrm{p}=0.0208^{*}\right)$.

\section{Practices and daily habits}

Approximately $84 \%$ of our participants showed an overall average to excellent practices. The most frequent practices the population engages in on a regular basis were drinking coffee (48.4\%), eating spicy food (31.2\%), drinking soft drinks (16.8\%), smoking (28.8\%), and using anti-inflammatory drugs (11.2\%).

We compared practices among different groups including gender, educational level and field of work using unpaired t-test, reported in Table 8. Females were found to have higher mean practice scores $(81.28 \%)$ in comparison to males $(72.72 \%)(\mathrm{p}<0.0001 *)$. The educational level and the field of work were not associated with better practice scores $(\mathrm{p}=0.2377, \mathrm{p}=0.8582$ respectively).

\section{Discussion}

To our knowledge, our study is the first of its kind to survey public KAPs with regards to $H$. pylori in the UAE. The limited awareness of $H$. pylori infection is alarming, given that the risk of $H$. pylori-induced gastric cancer can be reduced with early screening in high-risk populations and a simple course of antibiotics. Our study aimed to assess respondents' knowledge of gastric ulcers, their causes - specifically regarding $H$. pylori-, possible remedies and complications.

General knowledge regarding $H$. pylori General knowledge of the Sharjah population with regards to H. pylori gastric ulcers is poor. Knowledge about the common causes of gastric ulcers has also been found poor; while nearly half of the respondents recognized bacterial infections as a cause of gastric ulcers, only a quarter have previously heard of $H$. pylori. This is consistent with a study conducted in China where $22 \%$ and $35 \%$ of the seropositive and seronegative patients reported hearing about $H$. pylori, respectively (Xia et al., 2012). As reported in our results section, more participants (48.8\%) were aware of the association between $H$. pylori and gastric ulcers than those who recognized the relationship between $H$. pylori and gastric cancer (39\%), which shows a clear lack of knowledge of the attributable effects and the pathophysiology of this microorganism on the gastric mucosa, leading to gastric cancer. While curling ulcer is a common surgical entity defined as a gastric erosion due to reduced plasma volume following burns, only $3.6 \%$ recognize skin burns and major bleeding as a cause of stomach ulcers. Moreover, only 3\% of our respondents were aware that psychological stress can increase the risk of developing stomach ulcers. This is inconsistent with other studies in which stress was considered by the participants to be the highest risk factor for developing not only stomach ulcers (60.0\%) (CDC, 1997), but also gastric cancer (73.5\%) (Oh et al., 2009).

In our study, less than half of the participants recognized contaminated food and water as a means of transmission of the bacterium. This is consistent with other studies where participants had been asked how H. pylori infection can be acquired and only $24 \%$ correctly answered water and poor food preparations as the main sources (Chen et al., 2005). Another study has reported oral transmission with $12.6 \%$ when participants were asked about transmission (shin et al., 2013). This emphasizes the importance of water sanitation and hygienic practices such as handwashing, which should be promoted by the local health authorities to combat pathogenic infections caused by waterborne microorganisms (Wynne et al., 2013).

As expected, respondents with medical backgrounds were found to have more knowledge about $H$. pylori and its attributable effects than those from other non-medical backgrounds ( $\mathrm{p}<0.0001 *)$.

Discrepancy between males and females with regards to their knowledge and practices was significant, with females having better knowledge and practice scores. Females were found to have a higher average knowledge score $\left(\mathrm{p}=0.008^{*}\right)$ and engaged in practices that predisposed them to $H$. pylori much less frequently that their male counterparts ( $\left.<<0.0001^{*}\right)$.

\section{Attitudes towards H. pylori}

Patients were inquired on whether they suffer from symptoms of anemia, loss of weight, anorexia, dysphagia, odynophagia, melena, and hematemesis - also known as ALARM symptoms. These symptoms are commonly attributed to complicated gastric ulcer disease. Participants who suffered from ALARM symptoms were significantly better with regards to screening, avoidance, and 
management than those who suffer from mild or moderate symptoms $(p=0.0208 *)$. This could be justified by the discomfort associated with peptic ulcers leading to better attitudes to avoid suffering from these symptoms in the future and avoid risk of development of gastric ulcers or infection with $H$. pylori.

While $90 \%$ of subjects reported they would not ignore symptoms of stomach ulcers, only 33\% stated they would seek medical help. Moreover, $39 \%$ of respondents indicated they would not be willing to undergo frequent medical check-ups or screening to avoid infection with H. pylori. This could be due to their preference for nonmedical alternatives or herbal remedies, as is common in this part of the world, or concerns regarding medical costs for uninsured subjects. It is also likely that many patients assume their symptoms will improve eventually without the need for medical intervention.

To confirm a diagnosis of $H$. pylori infection, a confirmatory test such as biopsy urease testing via endoscopy, urea breath test or stool antigen test is recommended (Lehours, 2018) Endoscopy has a high sensitivity and specificity of $90 \%$ and $95 \%$, respectively (Malfertheiner et al., 2016). It is indicated in patients who suffer from upper gastrointestinal symptoms. Factors considered when choosing a confirmatory test include prevalence, cost, recent use of medications and test availability (Wang, 2015). Despite the associated discomfort, $76 \%$ of our participants said they would agree to undergo an endoscopy to diagnose $H$. pylori-associated stomach ulcers if necessary.

\section{Practices and daily habits}

Majority of our participants showed overall excellent practices $(84 \%)$. Good practices have been registered in another study in $74.5 \%$ of the population studied (Abongwa et al., 2017). Most participants (71.4\%) were found to engage in at least one of the practices listed that increase the risk of developing gastric ulcers such as smoking, drinking coffee regularly or using nonsteroidal anti-inflammatory drugs such as Aspirin or Ibuprofen. These practices not only predispose them to developing gastric ulcers but also increase the risk of future progression to gastric cancer. This was especially seen with coffee consumption and cigarette smoking. Interestingly, recent studies that analyzed the relation between cigarette smoking and $H$. pylori risk produced controversial results. While several studies found that the risk of $H$. pylori infection rose drastically with smoking (A-Ameri and Alkadasi, 2013; Ozden et al., 2004), one study suggested that it decreases the risk (Kanbay et al., 2005). Other studies revealed no association between smoking and $H$. pylori infection (Constanza et al., 2004; Woodward, 2000). A study in Germany suggested a dosedependent relationship of coffee consumption to active infection in that it can increase the risk of seroconversion around 5 times among those who drink more than 2 cups of caffeinated drinks per day (Brenner et al., 1999).

Handwashing before preparing meals is generally thought to be a good practice to reduce getting infections (Amaral et al., 2017). Unexpectedly however, Abebaw et. al linked a higher prevalence of $H$. pylori with hand washing before preparing meals (Abebaw et al., 2014). This is inconsistent with a study conducted by Lee et al. which showed no increased prevalence of $H$. pylori with handwashing (Lee et al., 2012). In our study, 62.2\% of respondents stated they would be willing to improve their self-hygienic practices to avoid being infected with H. pylori. This elucidates the need for more studies to delineate the link between $H$. pylori and handwashing to formulate future guidelines with regards to the matter at hand.

The difference between respondents from a medical background in comparison to those from non-medical backgrounds was not significant with regards to their practices $(p=0.8582)$. It was expected that due to practicing in the medical field, those participants would have more awareness regarding the effect of negative practices on the future development of gastric ulcers.

\section{Future directions}

We would also like to highlight the importance of a well-balanced nutritional diet and caloric distribution in symptomatic peptic ulcer patients; thus, additional studies which address this issue are necessary (Vomero and Colpo, 2014).

H. pylori antibiotic resistance is the main factor affecting efficacy of current therapeutic regimens, and the best alternative would be a prophylactic vaccine to potentially suppress the emergence of new cases of $H$. pylori-induced gastric ulcers (Abadi, 2016). There is no currently available vaccine against $H$. pylori. However, a vaccine known as IMX101 developed by Imevax (Sutton and Boag, 2019) has recently completed phase one trials. While more ambitious solutions such as vaccines could theoretically eliminate $H$. pylori infections, simpler approaches encompassing increasing awareness and education would go a long way in reducing disease burden and facilitating early detection and intervention programs.

\section{Limitations}

Our research used a convenience sampling method, which might have affected the generalizability of the results. This was manifested by our sample being confined to Sharjah. Not to mention, the relationship between health-related behavior and the characteristics measured by KAP surveys are complex and difficult to quantify. Furthermore, translation of the questionnaire was from English to Arabic and not the other way around. The questionnaire used was developed by the authors; a validated questionnaire was not used in this study. In order to confirm validity and reliability of the scale, further research is required to analyze the psychometric property of this questionnaire. In the future, it would be interesting to assess the self-risk of contracting $H$. pylori infection in the population.

In conclusion, our data demonstrated clear evidence about the lack of knowledge of the general population with regards to gastric ulcers generally and $H$. pylori-induced gastric ulcers, specifically. As such, it is imperative to implement educational outreach programs with the aim to increase public awareness about $H$. pylori, its routes of transmission and its health impacts. More 
importantly, screening and surveillance for early detection and intervention would be of great use in reducing the incidence of $H$. pylori-induced gastric ulcer and its complications such as gastric cancer. These could be easily avoided by ensuring early management with simple antibiotics.

\section{Author Contribution Statement}

A.M., M.A., L.O., H.B. contributed to data collection, data analysis, literature review and manuscript writing and editing. A.A. contributed to data collection, data analysis and literature review. M.F. contributed to data collection and literature review.

\section{Acknowledgements}

We would like to express our gratitude to Dr Amal Hussein from the Family and Community Medicine and Behavioral Sciences Department at the University of Sharjah for her continuous support throughout the project.

\section{Ethical approval}

The study was approved by the Ethics Committee in the University of Sharjah (Validation number: REC-1612-21-02-S).

\section{References}

A-Ameri GA, Alkadasi MN (2013). The prevalence of Helicobacter pylori and risk factors infection associated in Taiz city, Yemen. 8.

Abadi ATB (2016). Vaccine against Helicobacter pylori: Inevitable approach. World J Gastroenterol, 22, 3150.

Abebaw W, Kibret M, Abera B (2014). Prevalence and risk factors of $\mathrm{H}$. pylori from dyspeptic patients in northwest Ethiopia: A Hospital Based Cross-sectional Study. Asian Pac J Cancer Prev, 15, 4459-63.

Abongwa LE, Samje M, Antoine KS, et al (2017). Knowledge, Practice and Prevalence of Helicobacter Pylori Infection in the North West Region of Cameroon, pp 10.

Ahmed S, Salih M, Jafri W, Ali Shah H, Hamid S (2009). Helicobacter pylori infection: approach of primary care physicians in a developing country. BMC Gastroenterol, 9, doi: 10.1186/1471-230x-9-23

Amaral O, Fernandes I, Veiga N, et al (2017). Living conditions and Helicobacter pylori in adults. Bio Med Res Int, 2017, $1-5$.

Bray F, Ferlay J, Soerjomataram I, et al (2018). Global cancer statistics 2018: GLOBOCAN estimates of incidence and mortality worldwide for 36 cancers in 185 countries. $C A$ Cancer Clin, 68, 394-424.

Brenner H, Berg G, Lappus N, et al (1999). Alcohol consumption and Helicobacter pylori infection: Results from the German National Health and Nutrition Survey. Epidemiology, 10, 214-8.

Canbaz S, Sunter A, Peksen Y, Leblebicioglu H (2005). Survey of general practitioners' knowledge about Helicobacter pylori infection. BMC Gastroenterol, 5, doi: 10.1186/1471$230 \mathrm{x}-5-4$

Cancer today. (2020). Retrieved 15 December 2020, from https:// gco.iarc.fr/.

Cano-Contreras A, Rascón O, Amieva-Balmor M, et al (2018). Approach, attitudes, and knowledge of general practitioners in relation to Helicobacter pylori is inadequate. There is much room for improvement!. Revista De Gastroenterología De México (English Edition), 83, 16-24.

Chen SY, Liu TS, Fan XM, et al (2005). Epidemiological study of Helicobacter pylori infection and its risk factors in Shanghai. Zhonghua Yi Xue Za Zhi, 85, 802-6.

Constanza CM, Eduardo L-P, Javier T, et al (2004). Determinants of Helicobacter pylori seroprevalence in Mexican adolescents. Helicobacter, 9, 106-14.

Cover TL, Blaser MJ (2009). Helicobacter pylori in health and disease. Gastroenterology, 136, 1863-73.

Driscoll L, Brown H, Harris R, Oren E (2017). Population knowledge, attitude, and practice regarding Helicobacter pylori transmission and outcomes: A Literature Review. Front In Public Health, 5. doi: 10.3389/fpubh.2017.00144

Eshraghian A (2014). Epidemiology of Helicobacter pylori infection among the healthy population in Iran and countries of the Eastern Mediterranean Region: A systematic review of prevalence and risk factors. World J Gastroenterol, 20, 17618.

Ferlay J, Soerjomataram I, Dikshit R, et al (2015). Cancer incidence and mortality worldwide: Sources, methods and major patterns in GLOBOCAN 2012. Int J Cancer, 136, 359-86.

Ford AC, Gurusamy KS, Delaney B, Forman D, Moayyedi P (2016). Eradication therapy for peptic ulcer disease in Helicobacter pylori -positive people. Cochrane Database Syst Rev, https://doi.org/10.1002/14651858.CD003840. pub5.

Graham DY, Lu H, Yamaoka Y (2007). A Report Card to Grade Helicobacter pylori Therapy. Helicobacter, 12, 275-8.

Hooi JKY, Lai WY, et al (2017). Global prevalence of Helicobacter pylori infection: Systematic Review and Meta-Analysis. Gastroenterology, 153, 420-9.

Kanbay M, Gür G, Arslan H, Yilmaz U, Boyacioĝlu S (2005). The relationship of $\mathrm{ABO}$ blood group, age, gender, smoking, and Helicobacter pylori infection. Dig Dis Sci, 50, 1214-17.

Kim SY, Choi DJ, Chung J-W (2015). Antibiotic treatment for Helicobacter pylori: Is the end coming?. World $J$ Gastrointestinal Pharm Ther, 6, 183-98.

Knowledge About Causes of Peptic Ulcer Disease-United States, March-April (1997). (n.d.). Retrieved March 4, 2020, from https://www.cdc.gov/mmwr/preview/ mmwrhtml/00049679.htm.

Kuna L, Jakab J, Smolic R, et al (2019). Peptic ulcer disease: A Brief review of conventional therapy and herbal treatment options. JClin Med, 8, https://doi.org/10.3390/jcm8020179.

Lee YY, Ismail AW, Mustaffa N, et al (2012). Sociocultural and dietary practices among Malay subjects in the North-Eastern Region of Peninsular Malaysia: A Region of Low Prevalence of Helicobacter pylori Infection: Dietary Practices and Low H. pylori in Malays. Helicobacter, 17, 54-61.

Lehours P (2018). Actual diagnosis of Helicobacter pylori infection. Minerva Gastroenterologica E Dietologica, 64. doi: 10.23736/s1121-421x.18.02494-7.

Leodolter A, Kulig M, Brasch H, et al (2001). A meta-analysis comparing eradication, healing and relapse rates in patients with Helicobacter pylori-associated gastric or duodenal ulcer. Aliment Pharmacol Ther, 15, 1949-58.

Li Z, Wu C, Li L, et al (2017). Effect of long-term proton pump inhibitor administration on gastric mucosal atrophy: A metaanalysis. Saudi Journal of Gastroenterology: Official Journal of the Saudi Gastroenterology Association, 23, 222-8.

Malfertheiner P, Megraud F, O'Morain C, et al (2016). Management of Helicobacter pylori infection-the Maastricht V/Florence Consensus Report. Gut, 66, 6-30.

Moss SF (2017). The clinical evidence linking Helicobacter 
pylori to gastric cancer. Cell Mol Gastroenterol Hepatol, 3, 183-91.

Muhammad JS, Sugiyama T, Zaidi SF (2013). Gastric pathophysiological ins and outs of Helicobacter pylori: A review. J Pak Med Assoc, 63, 7.

Oh D-Y, Choi KS, Shin H-R, Bang Y-J (2009). Public awareness of gastric cancer risk factors and disease screening in a high risk region: A Population-Based Study. Cancer Res Treat, 41, 59.

Ozden A, Bozdayi G, Ozkan M, Köse K (2004). Changes in the seroepidemiological pattern of Helicobacter pylori infection over the last 10 years. Turk J Gastroenterol, 15, 156-8.

Plummer M, de Martel C, Vignat J, et al (2016). Global burden of cancers attributable to infections in 2012: A synthetic analysis. Lancet Global Health, 4, 609-16.

Shin D, Cho J, Kim S, et al (2013). Preferences for the "screen and treat" Strategy ofHelicobacter pylori toPrevent Gastric Cancer in Healthy Korean Populations. Helicobacter, 18, 262-9.

Sutton P, Boag J (2019). Status of vaccine research and development for Helicobacter pylori. Vaccine, 37, 7295-9.

Tsongo L, Nakavuma J, Mugasa C, Kamalha E (2015). Helicobacter pylori among patients with symptoms of gastroduodenal ulcer disease in rural Uganda. Infect Ecol Epidemiol, 5, 26785.

Vomero ND, Colpo E (2014). Nutritional care in peptic ulcer. ABCD. Arquivos Brasileiros de Cirurgia Digestiva (São Paulo), 27, 298-302.

Wang Y (2015). Diagnosis ofHelicobacter pyloriinfection: Current options and developments. World J Gastroenterol, 21, 11221.

Wong BCY, Lam SK, Wong WM, et al (2004). Helicobacter pylori eradication to prevent gastric cancer in a high-risk region of China: A Randomized Controlled Trial. JAMA, 291, 187-94.

Woodward M (2000). An investigation into factors associated with Helicobacter pylori infection. J Clin Epidemiol, 53, 175-81.

World Health Organization. A Guide to Developing Knowledge, Attitude and Practice Surveys. Switzerland: WHO (2008). Available from: http://apps.who.int/iris/ bitstream/10665/43790/1/9789241596176_eng.pdf.

Wu Y, Su T, Zhou X, et al (2020). Awareness and attitudes regarding Helicobacter pylori infection in Chinese physicians and public population: A national cross-sectional survey. Helicobacter, 25, doi: 10.1111/hel.12705.

Wynne A, Hastings EV, Colquhoun A, Chang H-J, Goodman KJ (2013). Untreated water and Helicobacter pylori: Perceptions and behaviors in a Northern Canadian community. Int $J$ Circumpolar Health, 72, 22447.

Xia P, Ma M-F, Wang W (2012). Status of Helicobacter pylori infection among migrant workers in Shijiazhuang, China. Asian Pac J Cancer Prev, 13, 1167-70.

This work is licensed under a Creative Commons AttributionNon Commercial 4.0 International License. 